\title{
Mutagenicity and Pathogenicity in Pseudomonas syringae pv. glycinea (Pseudomonas glycinea)
}

\author{
By M. D. THOMAS† AND J. V. LEARY* \\ Department of Plant Pathology, University of California, \\ Riverside, California 92521, U.S.A.
}

(Received 26 February 1980)

\begin{abstract}
The isolation and pathogenic response of various drug-resistant and auxotrophic mutants of strain PgB3 of Pseudomonas glycinea, the causal agent of bacterial blight of soybean, are reported. A mutagenesis procedure is described which allows efficient recovery of spontaneous, ethyl methanesulphonate-, hycanthone-, 2-aminopurine- and $N$-methyl- $N^{\prime}$-nitro$N$-nitrosoguanidine-induced mutants. While many of the auxotrophic mutants were avirulent, fully virulent histidine, adenine and methionine auxotrophic mutants were isolated. The virulence of certain methionine-requiring mutants did not correlate with the amount of methionine required by the mutant. In every instance where revertants to prototrophy were isolated, the revertant regained wild-type virulence.
\end{abstract}

\section{INTRODUCTION}

The premise that the growth of a pathogen in the plant is possible only under conditions of adequate nutrition and ineffective inhibition is the basis for Garber's nutrition-inhibition hypothesis (Garber, 1956). Many reports have supported this hypothesis, usually based on reduction of virulence in a limited number of induced auxotrophic mutants. Studies supporting the nutrition-inhibition hypothesis have been performed on Agrobacterium tumefaciens (Lippincott \& Lippincott, 1966, 1969), Corynebacterium faciens (Jacobs et al., 1965), C. michiganense (Ercolani, 1970), Erwinia aroidea (Garber et al., 1956), Pseudomonas solanacearum (Coplin et al., 1974), P. syringae (Ercolani, 1970), P. tabaci (Garber, 1959) and Xanthomonas oryzae (Yamaski et al., 1966). Virulence, when tested, was found to increase with the addition of the required nutrient during infection (Ercolani, 1970; Coplin et al., 1974). Restoration of prototrophy through reversion (Garber et al., 1956; Lippincott \& Lippincott, 1966, 1969) or transformation (Coplin et al., 1974; Yamaski et al., 1966) was reported to result always in restoration of virulence.

Although the nutrition-inhibition hypothesis holds for some nutritional requirements, it is not universal since numerous naturally occurring auxotrophic but fully virulent bacterial pathogens have been found. For example, E. amylovora and Xanthomonas pruni strains require nicotinic acid (Starr \& Mandel, 1950; M. D. Thomas \& J. V. Leary, unpublished results), methionine-requiring strains of $P$. glycinea have been isolated (N. T. Keen, personal communication), and many strains of $A$. tumefaciens have been isolated which have different, naturally occurring, auxotrophic requirements (Lippincott \& Lippincott, 1969). Also, Pugashetti \& Starr (1975) reported that avirulent auxotrophic mutants of E. amylovora were not virulent when inoculated along with their respective requirements and slightly less than half of the revertants of two avirulent mutants regained virulence, in contrast to earlier reports that restoration of prototrophy always results in restoration of virulence (Garber

$\dagger$ Present address: Department of Plant Pathology, University of Wisconsin, Madison, U.S.A. 
et al., 1956; Lippincott \& Lippincott, 1966; Coplin et al., 1974). Pugashetti \& Starr (1975) claimed $100 \%$ coinheritance of genes determining virulence when transconjugants were selected for prototrophy at selected loci. Langley \& Kado (1972) reported that auxotrophic mutants of a virulent $A$. tumefaciens wild-type strain varied in virulence. These avirulent mutants were not virulent when their requirements were supplied exogenously even though their doubling time in vivo (10 to $15 \mathrm{~h}$ ) was similar to that of the wild-type $(8.8 \mathrm{~h})$.

Non-nutritional mutants of phytopathogenic bacteria have been isolated which also show altered pathogenicity. $\alpha$-Methyltryptophan-resistant mutants of $P$. savastanoi, which do not accumulate indolyl-3-acetic acid, do not produce galls on oleander, even though they grow in the plant (Smidt \& Kosuge, 1978). Similarly, ultraviolet light-induced non-toxigenic mutants of $P$. phaseolicola give altered disease symptoms (Patil et al., 1974). These studies demonstrate that mutation is a potentially useful tool for investigating specific host-pathogen interactions, if the problem of loss of virulence accompanying auxotrophy can be resolved. Auxotrophic mutants should prove useful for disease interaction studies by providing markers for genetic analysis.

In this report, we present evidence that reduced virulence in auxotrophic mutants of $P$. glycinea is associated only with certain auxotrophic requirements. Further, we show that reduced virulence is not associated with the mutagen used, the type of mutation which results in the auxotrophic phenotype, or the concentration of the required nutrient available to the pathogen in vivo. Thus, the construction of virulent, genetically marked strains is possible. By enabling genetic analysis, such strains should provide information on specific host-pathogen interactions.

\section{METHODS}

Strains and media. Wild-type Pseudomonas glycinea strain PgB3 (race 8), and the complete and minimal media used, have been described earlier (Thomas \& Leary, 1980). Each nutritional supplement was added from filter-sterilized stock solutions to the minimal medium at a final concentration of $20 \mu \mathrm{g} \mathrm{ml}^{-\mathbf{1}}$. Antibiotic concentrations were as follows $\left(\mu \mathrm{g} \mathrm{ml}^{-1}\right)$ : rifampicin, 200; streptomycin, 200; nalidixic acid, 1000; carbenicillin, 1000; tetracycline, 50; D-cycloserine, 500; kasugamycin, 200.

Mutagenesis. Spontaneous drug-resistant mutants were obtained by plating 0.1 to $1.0 \mathrm{ml}$ of a suspension of exponential phase cells $\left[10^{8}\right.$ to $10^{9}$ colony-forming units (c.f.u.) $\left.\mathrm{ml}^{-1}\right]$ either directly on to antibiotic-containing medium or on to antibiotic gradient plates (Bryson \& Szybalski, 1952).

Induced auxotrophic mutants from wild-type or fully virulent drug-resistant strains were isolated by a procedure modified from that of Watson \& Holloway (1978). Virulent drug-resistant mutants, e.g. PgB3 nalA, resistant to nalidixic acid, were used for nutritional/virulence studies to allow genetic identification and to facilitate re-isolation from inoculated plants. Exponential phase cells $\left(10^{8}\right.$ to $10^{9}$ c.f.u. $\left.\mathrm{ml}^{-1}\right)$ in complete broth were exposed to one of the following mutagens: ethyl methanesulphonate (EMS), $1 \mathrm{mg} \mathrm{ml}^{-1}$ for $4 \mathrm{~h}$; $N$-methyl-N'-nitro- $N$-nitrosoguanidine (MNNG), $50 \mu \mathrm{g} \mathrm{ml}^{-1}$ for $30 \mathrm{~min}$ then washed once by centrifugation and resuspended in saline; hycanthone (HC), $1 \mathrm{mg} \mathrm{ml}^{-1}$ for $4 \mathrm{~h}$; 2-aminopurine (2-AP), $1 \mathrm{mg} \mathrm{ml}^{-1}$ for $4 \mathrm{~h}$. The mutagen-treated cultures were then diluted 1 to 20 into complete broth and shaken for 18 to $24 \mathrm{~h}$. A $1 \mathrm{ml}$ sample of this overnight culture was washed and shaken for an additional 18 to $24 \mathrm{~h} \mathrm{in} 10 \mathrm{ml}$ of nitrogen-free minimal broth or saline to achieve starvation. The cultures were then shaken for 18 to $24 \mathrm{~h}$ in minimal broth containing the original requirements of the strain mutagenized, plus 20 to $30 \mathrm{mg}$ carbenicillin $\mathrm{ml}^{-1}$ (carbenicillin counterselection). The cultures were finally washed twice and resuspended with vigorous agitation in distilled water (providing an osmotic shock), and plated without further dilution on to complete agar. Complete agar master plates were inoculated with the surviving colonies and the master plates were replicaplated with a multi-pronged inoculating device to variously supplemented minimal agar plates to distinguish the mutants and to determine their requirements. The mutants were then single-colony cloned and tested for stability of requirement, reversion frequency and pathogenicity. Spontaneous auxotrophic mutants were isolated in the same manner without the use of mutagens.

Pathogenicity. Soybean cultivars Harosoy and Flambeau, which give a susceptible response to PgB3, were inoculated with cells grown from a single colony as reported previously (Thomas \& Leary, 1980). Disease symptoms were indexed with respect to severity from 0 to 4 by comparison with symptoms occurring on plants treated with either water (rated 0 or, occasionally, 1) or wild-type PgB3 cells (rated 3 or 4). Avirulence thus refers to a lack of disease symptoms and should not be confused with the avirulent, hypersensitive 
resistant response (Cross et al., 1966) observed with incompatible pathogen-host combinations. A minimum of four inoculations per plant were made on two or three plants per test; tests with variable results were repeated a minimum of three times.

Mutational characterization. To determine the type of mutational lesion, $0 \cdot 1 \mathrm{ml}$ samples of an earlyexponential phase, auxotrophic mutant culture in complete broth were spread on several plates of minimal agar plus the nutrients required by the parent. This gave a faint background lawn, allowing sufficient growth for revertants to appear. Crystals of HC (a frameshift mutagen), 2-AP (a base transition mutagen) or MNNG (a transition and transversion mutagen) were placed singly in the centre of different plates. Mutants not revertible by any of these three mutagens were assumed to be carrying deletion mutations (Miller, 1972). Determination of growth on methionine and histidine pathway intermediates was determined by streaking the appropriate mutant on minimal agar plates supplemented with histidinol, histidinol phosphate, homoserine, cystathionine, cysteine or 5-methyltetrahydrofolic acid.

\section{RESULTS}

Virulence of drug-resistant mutants

Spontaneous carbenicillin-resistant mutants arising from $\mathrm{PgB} 3$ cells were isolated at a frequency of $10^{-5}$ to $10^{-6}$ per c.f.u. Mutants resistant to rifampicin or D-cycloserine were isolated at $10^{-7}$ to $10^{-8}$ per c.f.u. Spontaneous mutants resistant to streptomycin or nalidixic acid could not be isolated by direct plating of cells at densities of less than $10^{10}$ c.f.u. $\mathrm{ml}^{-1}$, but could be isolated using the gradient plate technique (Bryson \& Szybalski, 1952). Mutants resistant to either tetracycline or kasugamycin were isolated with the gradient plate technique and these mutants could be maintained on medium containing the antibiotic. They lost resistance when transferred to antibiotic-free medium. In no instance was virulence altered by resistance to one or any two of the antibiotics.

\section{Recovery of auxotrophic mutants}

The efficiency of recovery of auxotrophic mutants with the carbenicillin counterselection procedure varied among individual replicates as well as with the mutagen used. Up to $80 \%$ of the colonies after EMS or MNNG mutagenesis were auxotrophic mutants, whereas with spontaneous, $\mathrm{HC}$ or 2-AP mutagenesis the maximum recovery frequencies were 25 to $30 \%$.

In each of 40 mutagenesis experiments using EMS, the frequency of mutant phenotypes was remarkably consistent. Approximately $33 \%$ of the determinable auxotrophic mutants isolated in a given mutation series responded to adenine, $20 \%$ to isoleucine-valine, $18 \%$ to leucine, $10 \%$ to methionine, $8 \%$ to isoleucine, $5 \%$ to histidine and $4 \%$ to other growth factors. Spontaneous and HC- or 2-AP-induced mutant phenotypes appeared to occur at similar frequencies; however, the total number of mutants isolated in a given series by these methods was not great enough to provide significant comparison. Phenotypes of mutants induced by MNNG occurred at frequencies similar to EMS-induced mutants with only a slight increase in the number of undeterminable phenotypes. Specific classes of mutants could be isolated by supplementing the carbenicillin counterselection broth with various growth requirements.

\section{Virulence of auxotrophic mutants}

Whether because of diffusion, translocation or utilization by the plant, it was impossible to maintain the level of exogenously supplied supplement needed by the auxotrophic mutant in the leaf during pathogenicity tests. Results of this type of pathogenicity test were not consistent and therefore all pathogenicity inoculations were made without supplements. Virulence of various EMS-induced mutants of PgB3, PgB3 nalA1 and PgB3 nalA2 is compared in Table 1 . Nearly all histidine-requiring (His) mutants, $50 \%$ of the Met mutants and about $15 \%$ of the Ade mutants were as virulent as the wild-type PgB3. None of the other mutants were as virulent as the wild-type. Virulence patterns of spontaneous and HC- or 
Table 1. Virulence of EMS-induced mutants of $P$. glycinea strains $\mathrm{PgB} 3, \mathrm{PgB} 3$ nalA1 and $\mathrm{PgB} 3$ nalA2 (disease index 4)

\begin{tabular}{cccc} 
& \multicolumn{3}{c}{$\begin{array}{c}\text { Total no. of individual mutants in each } \\
\text { virulence class }\end{array}$} \\
\cline { 2 - 4 } Phenotype* & $\begin{array}{c}\text { Avirulent } \\
\text { (DI† 0 to 1) }\end{array}$ & $\begin{array}{c}\text { Intermediate } \\
\text { (DI 2) }\end{array}$ & $\begin{array}{c}\text { Virulent } \\
\text { (DI 3 or 4) }\end{array}$ \\
Ade & 25 & 10 & 6 \\
His & 1 & 0 & 30 \\
Ile & 31 & 2 & 0 \\
Ilv & 48 & 5 & 0 \\
Leu & 29 & 4 & 0 \\
Met & 13 & 5 & 13 \\
Phe & 4 & 1 & 0 \\
Ser & 8 & 5 & 0 \\
Ura & 6 & 2 & 0
\end{tabular}

* Nutrient required: Ade, adenine; His, histidine; Ile, isoleucine; Ilv, isoleucine and valine; Leu, leucine; Met, methionine; Phe, phenylalanine; Ser, serine; Ura, uracil.

† Disease index (DI); water control, 0 to 1; wild-type control, 3 to 4.

Table 2. Virulence of spontaneous, $H C$ - or $2-A P$-induced mutants of $P$. glycinea $\mathrm{PgB} 3$ and derivatives

$\begin{array}{cccc}\text { Phenotype } & \begin{array}{c}\text { No. of independently isolated mutants, } \\ \text { listed by disease index* }\end{array} & \begin{array}{c}\text { Hycanthone- } \\ \text { induced }\end{array} & \begin{array}{c}\text { 2-aminopurine- } \\ \text { induced }\end{array} \\ \text { Ade } & 12,8,6 & 4,0,1 & 6,1,0 \\ \text { His } & 0,0,6 & 0,0,2 & -2 \\ \text { Ile } & 1,0,0 & - & 2,0,0 \\ \text { Ilv } & 4,1,0 & 1,1,0 & 1,0,0 \\ \text { Leu } & 14,2,0 & 3,0,0 & - \\ \text { Met } & 0,1,4 & 2,0,1 & 7,2,4 \\ \text { Phe } & 2,0,0 & - & - \\ \text { Ser } & 4,2,0 & - & - \\ \text { Ura } & 2,0 & -\end{array}$

* In each triplet $(x, y, z), x$ is the number of mutants having disease index 0 to $1, y$ those having disease index 2 , and $z$ those having disease index 3 to 4 . Parental strains had a disease index of 3 to 4 . - , No mutants detected.

2-AP-induced mutants (Table 2) paralleled the virulence patterns of EMS-induced mutants. To study the virulence pattern associated with the Met mutants in depth, a series of MNNG mutageneses was performed on PgB3 nalA1 and PgB3 nalA2 using carbenicillin counterselection medium supplemented with adenine, glycine, histidine, isoleucine, leucine, phenylalanine, serine and uracil. Over $400 \mathrm{Met}$ mutants were thus isolated; 50 were selected at random and tested for virulence (Table 3). The same pattern of virulence was seen in this collection of MNNG-induced mutants as in the EMS-induced Met mutants. Representative samples of Met mutants, selected from those listed in Table 4, were tested to determine if their virulence pattern corresponded to growth on low concentrations of methionine. Both virulent and avirulent Met mutants responded either well or weakly to low concentrations of methionine. Consequently, virulence cannot be attributed to a low level methionine requirement and avirulence cannot be attributed to a high level methionine requirement (Table 5).

To determine whether loss of virulence was due to the auxotrophic mutation or a concomitant undetected mutation, a series of revertants was isolated. The phenotypic distribu- 
Table 3. Virulence of $M N N G$-induced methionine-requiring mutants of $P$. glycinea strains $\mathrm{PgB} 3$ nalAl and $\mathrm{PgB} 3$ nalA2

\begin{tabular}{cccc} 
& \multicolumn{3}{c}{$\begin{array}{c}\text { No. of mutants isolated in each } \\
\text { virulence class }\end{array}$} \\
Strain & $\begin{array}{c}\text { Avirulent } \\
\text { (DI* 0 or 1) }\end{array}$ & $\begin{array}{c}\text { Intermediate } \\
\text { (DI 2) }\end{array}$ & $\begin{array}{c}\text { Virulent } \\
\text { (DI 3 or 4) }\end{array}$ \\
PgB3 nalA1 & 8 & 8 & 5 \\
PgB3 nalA2 & 10 & 6 & 13
\end{tabular}

* Disease index (DI): water control, 0 to 1 ; parental strains, 3 to 4 .

Table 4. Properties of a representative sample of methionine-requiring mutants of $P$. glycinea $\mathrm{PgB} 3$ and derivatives

\begin{tabular}{|c|c|c|c|c|c|}
\hline \multirow[b]{2}{*}{ Mutant genotype } & \multirow[b]{2}{*}{ Mutagen } & \multirow{2}{*}{$\begin{array}{l}\text { Disease } \\
\text { index* }\end{array}$} & \multicolumn{3}{|c|}{ Revertibility $\dagger$} \\
\hline & & & MNNG & $\mathrm{HC}$ & 2-AP \\
\hline PgB3 nalA2 met-2 & EMS & 4 & - & - & - \\
\hline PgB3 nalA2 met-5 & EMS & 4 & + & - & - \\
\hline PgB3 nalA2 met-15 & EMS & 4 & - & - & - \\
\hline PgB3 nalA 2 met-18 & EMS & 0 & - & - & - \\
\hline PgB3 nalA2 met-19 & EMS & 4 & - & - & - \\
\hline PgB3 nalA2 met-20 & EMS & 3 & + & - & + \\
\hline PgB3 nalA2 met-25 & EMS & 4 & - & - & - \\
\hline PgB3 nalA 2 met-32 & EMS & 1 & + & - & - \\
\hline PgB3 nalA2 met-35 & EMS & 4 & + & - & \pm \\
\hline PgB3 nalA 2 met -36 & EMS & 0 & \pm & \pm & $\overline{ \pm}$ \\
\hline PgB3 nalA1 met-37 & None & 2 & - & - & - \\
\hline PgB3 met-38 & EMS & 4 & - & - & - \\
\hline PgB3 nalA2 met-48 & MNNG & $\mathbf{0}$ & - & - & - \\
\hline PgB3 nalA2 met-51 & MNNG & 0 & - & $\rightarrow$ & - \\
\hline PgB3 nalA2 met-62 & MNNG & 4 & + & \pm & + \\
\hline PgB3 nalA2 met-90 & MNNG & 0 & - & $=$ & - \\
\hline
\end{tabular}

* Water control, 0 to 1 ; parental strains, 3 to 4.

$\dagger-$, Not revertible; + , revertible; \pm , intermediate.

Table 5. Growth yield of P. glycinea $\mathrm{PgB} 3 \mathrm{Met}$ mutants on low concentrations of methionine

\begin{tabular}{|c|c|c|c|c|}
\hline \multirow{3}{*}{$\begin{array}{l}\text { Methionine } \\
\text { allele }\end{array}$} & \multirow{3}{*}{$\begin{array}{l}\text { Disease } \\
\text { index* }\end{array}$} & \multicolumn{3}{|c|}{$\begin{array}{c}A_{600} \text { after } \\
24 \mathrm{~h} \text { growth at } 25^{\circ} \mathrm{C} \dagger\end{array}$} \\
\hline & & \multicolumn{3}{|c|}{ Methionine concn $\left(\mu \mathrm{g} \mathrm{ml}^{-1}\right)$} \\
\hline & & 0 & 1 & 10 \\
\hline PgB3 $\ddagger$ & 4 & $1 \cdot 0$ & $1 \cdot 3$ & $1 \cdot 2$ \\
\hline met-2 & 4 & $0 \cdot 1$ & $0 \cdot 3$ & 0.9 \\
\hline met-15 & 4 & $0 \cdot 2$ & 0.4 & $1 \cdot 2$ \\
\hline met-18 & 1 & $0 \cdot 1$ & $0 \cdot 2$ & $1 \cdot 0$ \\
\hline met-19 & 4 & $0 \cdot 1$ & $0 \cdot \overline{3}$ & $1 \cdot 1$ \\
\hline met-25 & 4 & $0 \cdot 1$ & $0 \cdot 2$ & $0 \cdot 3$ \\
\hline met-32 & 1 & 0.2 & $0 \cdot 3$ & $1 \cdot 2$ \\
\hline$m e t-35$ & 4 & $0 \cdot 1$ & $0 \cdot 3$ & $1 \cdot 0$ \\
\hline$m e t-36$ & 0 & $0 \cdot 1$ & $0 \cdot 4$ & $1 \cdot 2$ \\
\hline
\end{tabular}


tion of 39 revertants of avirulent auxotrophic mutants was as follows: 8 Ade, 1 His, 4 Ile, $5 \mathrm{Ilv}, 6 \mathrm{Leu}, 12 \mathrm{Met}, 2 \mathrm{Phe}, 1 \mathrm{Ser}$. One revertant clone per mutant was tested for pathogenicity and, in every case, revertants had regained full wild-type virulence.

\section{DISCUSSION}

The existence of $P$. glycinea PgB3 mutants requiring adenine, isoleucine, leucine, phenylalanine, serine or uracil, all having reduced virulence, supports the nutrition-inhibition hypothesis. Lack of similar reduction in the virulence of other types of deficient mutants, i.e. drug resistance and carbohydrate utilization (Thomas \& Leary, 1980), further supports this hypothesis. However, it is contradictory that 38 out of 39 His mutants (Tables 1 and 2) were as virulent as the wild-type. The most likely explanation for this observation is that the plant supplies sufficient histidine for growth of the His mutants, but does not supply sufficient quantities of other growth requirements. There has been little work on the concentrations of various growth requirements in soybean to support this possibility. It is also not clear what fractions of the plant's biochemical pools are available to an intercellular pathogen during infection. Duke et al. (1978) have measured free amino acid pools in soybean under various conditions. They found in $5 \mathrm{~d}$-old soybean leaf axes, grown at $23{ }^{\circ} \mathrm{C}$, the following concentrations $\left[\mu \mathrm{mol}\left(\mathrm{g}_{\text {fresh }} \mathrm{wt}\right)^{-1}\right]$ : serine, $3 \cdot 2$; valine, $5 \cdot 9$; isoleucine, $2 \cdot 3$; leucine, $0 \cdot 9$; histidine, $5 \cdot 5 ;$ methionine, $0 \cdot 1$. While only suggestive, these concentrations may explain the virulence of His mutants, but they cannot explain the virulence of $50 \%$ of the Met mutants.

The virulence of $50 \%$ of the Met mutants cannot be attributed to a requirement for a lower concentration of methionine, since their growth on low concentrations of methionine is similar to that of the avirulent Met mutants (Table 5). The virulence also is not due to a less stringent requirement for methionine because the extent of growth of Met mutants for periods of up to 2 weeks under conditions of methionine starvation does not correspond to the degree of virulence (results not shown). Also, since there was no correlation between virulence and the response of Met mutants to methionine metabolic intermediates, virulence cannot be explained by differential concentrations of methionine intermediates in the plant. In contrast, revertants of avirulent Met mutants can be isolated; these revertants are virulent, demonstrating that avirulence is not due to an additional undetected mutation. Finally, the type of mutation does not correspond to loss of virulence; non-revertible, presumed deletion mutants requiring methionine also show characteristic variable virulence patterns (Table 4). Attempts to identify the particular loci have been unsuccessful since none of the Met mutants respond to the methionine intermediates tested.

In view of these findings, it is possible that specific genetic loci responsible for virulence are included in, coincident with, or regulated by, genes determining selectable phenotypes. Thus, the location of the mutational event in potentially virulent auxotrophic PgB3 mutants (Ade, Met, His) may be responsible for changes in virulence. Restoration of virulence in revertants of avirulent auxotrophs argues against the involvement of plasmids.

We have shown that neither the isolation of auxotrophic mutants in itself nor the type of mutagen used necessarily cause reduction in virulence. As previously reported (Thomas \& Leary, 1980), we have constructed multiply-marked mutants which are fully as virulent on soybean as the wild-type, by selecting auxotrophic mutants which retain virulence and screening these mutants for virulence before further mutagenesis. These mutants, which have two or three auxotrophic requirements and one or more drug resistance or carbohydrate utilization markers, can provide important information on the spread of disease under field conditions. Also, they may provide insight into both the frequency of genetic recombination among $P$. glycinea and other pathogens or saprophytes in the field, and the role of genetic recombination in the occurrence of new races or pathotypes of a pathogen. 
This work forms part of the Ph.D. thesis submitted to the University of California by M.D.T.

\section{REFERENCES}

BRyson, V. \& Szybalski, W. (1952). Microbial selection. Science 116, 45-51.

Coplin, D. L., Sequeira, L. \& Hanson, R. S. (1974). Pseudomonas solanacearum: virulence of biochemical mutants. Canadian Journal of Microbiology 20, 519-529.

Cross, J. E., Kennedy, B. W., Lambert, J. W. \& CoOPER, R. L. (1966). Pathogenic races of the bacterial blight pathogen of soybeans, Pseudomonas glycinea. Plant Disease Reporter 50, 557560.

Duke, S. H., Schrader, L. E. \& Miller, M. G. (1978). Low temperature effects on soybean [Glycine max (L.) Merr. cv. Wells] free amino acid pools during germination. Plant Physiology 62, 642-647.

ErCOLANI, G. L. (1970). Bacterial canker of tomato. III. The effect of auxotrophic mutation on the virulence of Corynebacterium michiganense (E. F. Sm.) Jens. Phytopathologia mediterranea 9, 145150.

GARBER, E. D. (1956). A nutrition inhibition hypothesis of pathogenicity. American Naturalist 90, 183-194.

GarBer, E. D. (1959). Further observations on biochemical mutants of Pseudomonas tabaci. Botanical Gazette 120, 157-161.

Garber, E. D., Shaeffer, S. G. \& Goldman, M. (1956). The virulence of biochemical mutants of Erwinia aroidea for varieties of radish and turnip. Journal of General Microbiology 14, 261-267.

JACOBS, S. E., HABISH, H. A. \& DADD, A. H. (1965). Studies on induced mutants of Corynebacterium faciens and on their pathogenicity in comparison with that of 'natural' strains. Annals of Applied Biology 56, 161-170.

LANGLeY, R. A. \& Kado, C. I. (1972). Studies on Agrobacterium tumefaciens. Conditions for mutagenesis by $N$-methyl- $N^{\prime}$-nitro- $N$-nitrosoguanidine and relationships of $A$. tumefaciens mutants to crown-gall tumor induction. Mutation Research 14, 277-286.
LipPincotT, B. B. \& LippincotT, J. A. (1966). Characteristics of Agrobacterium tumefaciens auxotrophic mutant infectivity. Journal of Bacteriology 92, 937-945.

LippincotT, J. A. \& LippincotT, B. B. (1969). Tumour-initiating ability and nutrition in the genus Agrobacterium. Journal of General Microbiology 59, 57-75.

Miller, J.H. (1972). Experiments in Molecular Genetics. New York: Cold Spring Harbor Laboratory.

Patil, S. S., Hayward, A. C. \& Emmons, R. (1974). An ultraviolet-induced nontoxigenic mutant of Pseudomonas phaseolicola of altered pathogenicity. Phytopathology 64, 590-595.

Pugashetti, B. K. \& Starr, M. P. (1975). Conjugational transfer of genes determining plant virulence in Erwinia amylovora. Journal of Bacteriology 122, 485-491.

SmidT, M. \& Kosuge, T. (1978). The role of indole3-acetic acid accumulation by alpha methyl tryptophan-resistant mutants of Pseudomonas savastanoi in gall formation on oleanders. Physiological Plant Pathology 13, 203-214.

StarR, M. P. \& MANDEL, M. (1950). The nutrition of phytopathogenic bacteria. IV. Minimal nutritive requirements of the genus Erwinia. Journal of Bacteriology 60, 669-672.

Thomas, M. D. \& Leary, J. V. (1980). A new race of Pseudomonas glycinea. Phytopathology 70, 310 312.

Watson, J. M. \& Holloway, B. W. (1978). Chromosome mapping in Pseudomonas aeruginosa PAT. Journal of Bacteriology 133, 1113-1125.

Yamaski, Y., Murata, N. \& SuWa, T. (1966). Restoration of lost virulence of leucine-requiring mutants of Xanthomonas oryzae by DNAmediated transformation. Nihon Gakushiin Proceedings 42, 946-949. 